PREPARED FOR THE U.S. DEPARTMENT OF ENERGY, UNDER CONTRACT DE-AC02-76CH03073

PPPL-3859

PPPL-3859

UC-70

Experimental Investigation of $m=1$ Diocotron Mode Growth at Low Electron Densities

by

Stephen F. Paul, Kyle Morrison, and Ronald C. Davidson

August 2003

NM|

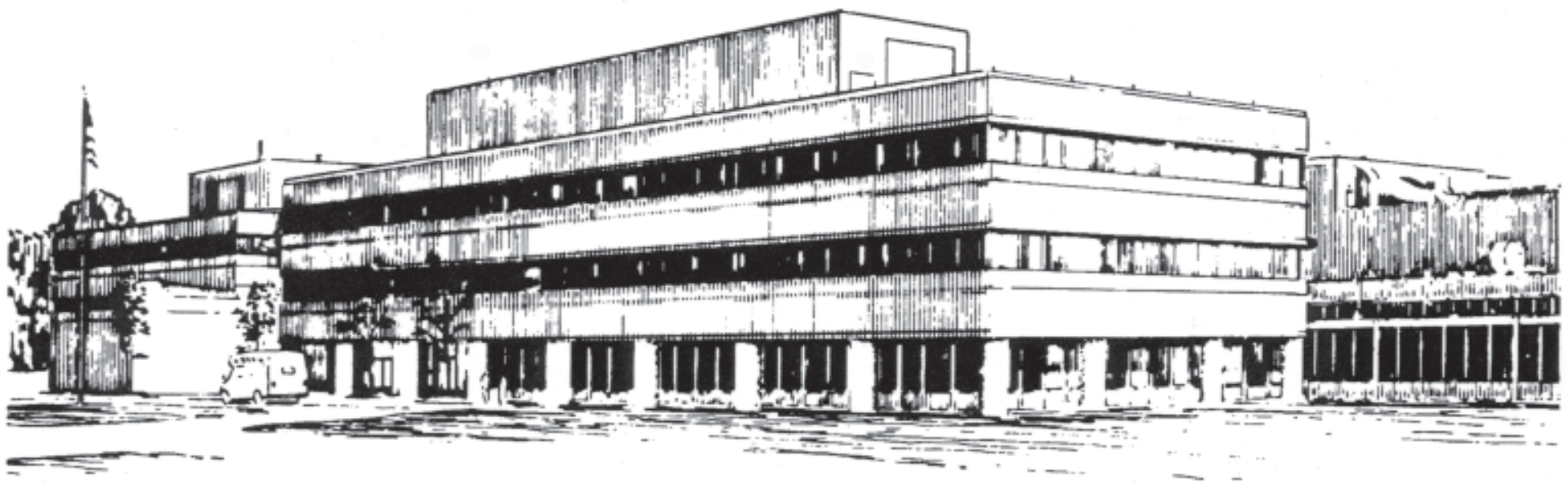

PRINCETON PLASMA PHYSICS LABORATORY PRINCETON UNIVERSITY, PRINCETON, NEW JERSEY 


\section{PPPL Reports Disclaimer}

This report was prepared as an account of work sponsored by an agency of the United States Government. Neither the United States Government nor any agency thereof, nor any of their employees, makes any warranty, express or implied, or assumes any legal liability or responsibility for the accuracy, completeness, or usefulness of any information, apparatus, product, or process disclosed, or represents that its use would not infringe privately owned rights. Reference herein to any specific commercial product, process, or service by trade name, trademark, manufacturer, or otherwise, does not necessarily constitute or imply its endorsement, recommendation, or favoring by the United States Government or any agency thereof. The views and opinions of authors expressed herein do not necessarily state or reflect those of the United States Government or any agency thereof.

\section{Availability}

This report is posted on the U.S. Department of Energy's Princeton Plasma Physics Laboratory Publications and Reports web site in Fiscal Year 2003. The home page for PPPL Reports and Publications is: http://www.pppl.gov/pub_report/

DOE and DOE Contractors can obtain copies of this report from:

U.S. Department of Energy

Office of Scientific and Technical Information

DOE Technical Information Services (DTIS)

P.O. Box 62

Oak Ridge, TN 37831

Telephone: (865) 576-8401

Fax: (865) 576-5728

Email: reports@adonis.osti.gov

This report is available to the general public from:

National Technical Information Service

U.S. Department of Commerce

5285 Port Royal Road

Springfield, VA 22161

Telephone: $1-800-553-6847$ or

(703) $605-6000$

Fax: (703) 321-8547

Internet: http://www.ntis.gov/ordering.htm 


\title{
Experimental Investigation of $m=1$ Diocotron Mode Growth at Low Electron Densities
}

\author{
Stephen F. Paul, Kyle Morrison, Ronald C. Davidson \\ Plasma Physics Laboratory, Princeton University, Princeton, New Jersey 08543, USA
}

\begin{abstract}
Previous experiments on the Electron Diffusion Gauge showed that the diocotron mode damping increases with higher neutral gas filling pressure. Yet the energy dissipated from a rotating plasma by collisions with neutrals is predicted to excite the mode. To resolve this, experiments have been conducted to examine the coupling between expansion and the $m=1$ diocotron mode. Results from recent experiments have shown interesting phenomena: 1) The degree and sensitivity of mode growth is observed to be strongly dependent on filament conditions. Mode growth rates of nearly $20 \mathrm{sec}^{-1}$ have been observed even with negligible resistive drive. Specifically, at low filament bias voltages (and correspondingly low electron densities $\sim 1-2 \times 10^{7}$ electrons/cm), the mode growth is very sensitive to the heating voltage across the filament, even though changes in filament heating voltage barely affect the plasma expansion, the plasma density profile, the filament emission, or the resulting electron density. 2) At low neutral gas pressure $\left(<10^{-9}\right.$ Torr $)$, the diocotron mode growth rate increases with neutral pressure. However, the growth rate is several orders of magnitude larger than theoretical predictions.
\end{abstract}

\section{INTRODUCTION}

Electron plasmas confined in Malmberg-Penning traps have been used to investigate important fundamental non-neutral plasma phenomena $[1,2,3,4]$. The research emphasis for the Electron Diffusion Gauge (EDG) experiment has been the investigation of the effects of collisions between the confined pure electron plasma and a low-pressure neutral gas, with the goal of using the measured interaction to determine the neutral gas pressure over a wide range. The expansion of the plasma column has been related theoretically to the rate of collisions between the electrons and the neutrals $[5,6]$. The expansion rate has also been measured experimentally on the EDG experiment $[7,8]$ using a Faraday cup collector and observed to scale classically [9] at relatively high neutral pressures $\left(P>10^{-6}\right)$, but this method requires hundreds of repeated discharges to determine the expansion rate. This approach was not only time-consuming, but required excellent plasma reproducibility and low measurement noise. The scatter in the data and the presence of asymmetry-induced expansion limited the detection of neutral pressure in the EDG via this technique to $P>10^{-8}$ Torr.

As an alternative, the possibility of a non-destructive pressure measurement using the dependence of the $m=1$ diocotron mode growth rate on background gas pressure has been explored more recently [8]. Here "diocotron mode" means the low-frequency, electrostatic oscillation with azimuthal mode number $m=1$. As is typical in MalmbergPenning traps, a uniform axial magnetic field provides the radial confinement, and applied electric potentials on cylindrical end-electrodes provide the axial confinement. For 
small-amplitude perturbations, the oscillations result from the plasma column being displaced from and precessing about the trap axis (the center of symmetry of the cylindrical electrodes that surround the plasma). The precession occurs at the diocotron mode frequency; the mode amplitude $A$ is the distance from the center of the plasma column to the trap axis; and the growth rate is $(1 / A) d A / d t$. The advantage of this method is that the need to terminate the plasma and measure the density profile at successive times in the evolution is avoided because the entire mode evolution is recorded in one discharge. In the absence of electron-neutral collisions, the diocotron mode is predicted to be marginally stable. When collisions are present, they dissipate energy from the plasma column, forcing it to move nearer to the surrounding conducting wall, (i.e., the mode amplitude should grow). A calculation assuming that the expansion of the plasma is much slower than the growth time has predicted an instability growth rate that scales linearly with neutral pressure $[10,11]$,

$$
\gamma_{n}=\frac{v_{e n}}{\omega_{c e}} \omega_{\infty}
$$

where $\omega_{\infty}$ is the frequency of the diocotron mode for an infinite-length plasma column and $v_{e n}$ is the electron-neutral collision frequency. For the plasma parameters in the EDG and a neutral gas pressure of $P=5 \times 10^{-10}$ Torr, the mode growth rate is predicted to be small: about $10^{-4} \mathrm{sec}^{-1}$. In the early EDG experiments [8], the mode was observed to decay rather than grow in most cases, with the damping rate increasing with both pressure and electron density. Damping of trapped-particle modes (analogous to oppositely phased diocotron modes) has been observed in others' experiments and explained by associated particle transport resulting from applied electric asymmetries [12]. The damping results from velocity scattering of particles near the separatrix that are trapped as a result of the applied asymmetry. The damping of diocotron modes in EDG may be caused by trapped particles resulting from intrinsic magnetic asymmetries as well.

More recent experiments showed that at low pressures $\left(5 \times 10^{-11}\right.$ Torr $<\mathrm{P}<4 \times$ $10^{-8}$ Torr) where asymmetry-induced transport dominates, only a weak, $P^{1 / 4}$ pressure dependence on damping is observed. However, in isolated cases ( $P=2-4 \times 10^{-9}$ Torr $)$ where mode growth was resistively forced, the growth rate was seen to be very sensitive to changes in pressure. The purpose of this paper is to examine whether this sensitivity of the growth rate to neutral pressure can be observed, reproduced, and controlled at much lower pressures.

The EDG trap and its operation are similar to that in other experiments and has been described previously [7]. The co-linear, cylindrical copper trap electrodes have an inner radius of $R_{w}=2.54 \mathrm{~cm}$, and the applied potentials at the end-electrodes are $-145 \mathrm{~V}$. The magnetic field, variable up to $1 \mathrm{kG}$, is generated with a solenoid whose axial current profile is adjusted so that the field in the trap region is constant to within $0.2 \%$ of the maximum field. The trap assembly is enclosed in an aluminum vacuum chamber that is evacuated to nearly $3 \times 10^{-11}$ Torr with a turbomolecular pump and a cryogenic pump. Helium gas is bled into the chamber with a precision metering valve and the fill pressure is measured with an Ionivac extractor gauge.

The trapped electron plasma has an initial density in the range $8 \times 10^{6} \mathrm{~cm}^{-3}<n<$ $3 \times 10^{7} \mathrm{~cm}^{-3}$, temperature $T \sim 1-2 \mathrm{eV}$, radius $R_{p} \simeq 0.6 \mathrm{~cm}$, and length $L_{p} \simeq 15 \mathrm{~cm}$. For these parameters, the Debye length $\lambda_{D}=\left(T / 4 \pi n e^{2}\right)^{1 / 2}$ is smaller than the plasma 
radius $\left(R_{p} \simeq 6 \lambda_{D}\right)$ and $\omega_{p e}^{2} / \omega_{c e}^{2}<0.01$, where $\omega_{p e}=\left(4 \pi n e^{2} / m_{e}\right)^{1 / 2}$ is the electron plasma frequency, and $\omega_{c e}=e B / m_{e} c$ is the electron cyclotron frequency. The $m=1$ diocotron frequency ranges from $10 \mathrm{kHz}$ to $100 \mathrm{kHz}$.

One of the copper cylinders that surrounds the plasma is divided into half-cylinders, and the mode amplitude is determined from the current induced by the precessing column to the half-cylinders [13]. Any odd-numbered diocotron mode $(m=1,3, \ldots)$ can be measured with this diagnostic, but the $m=1$ mode is dominant in the EDG.

\section{SENSITIVITY OF THE $M=1$ DIOCOTRON MODE TO FILAMENT CONDITIONS AND BACKGROUND PRESSURE}

As mentioned above, collisions with neutral particles can apply a torque, causing the column to expand symmetrically, or dissipate energy from the plasma column, displacing it towards the surrounding conducting wall. To isolate and improve the sensitivity of diocotron mode behavior to pressure, the EDG was operated at low electron density to minimize plasma expansion.

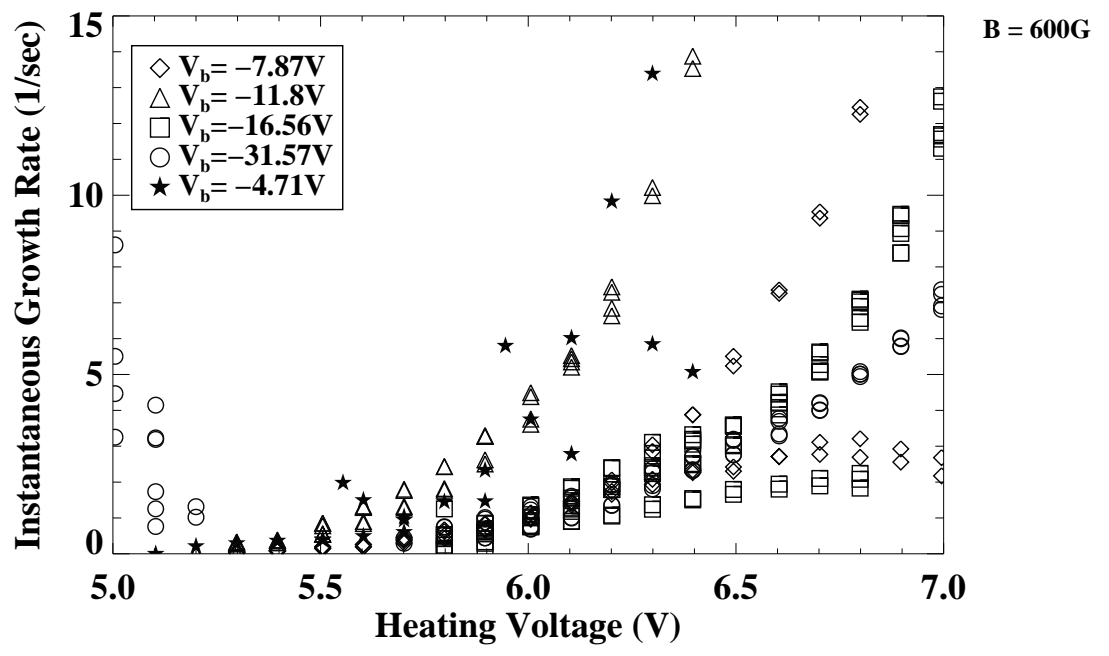

FIGURE 1. Plot of growth rate of the diocotron mode versus filament heating voltage for several values of filament bias voltage. The growth rate is measured at the point where the measured mode amplitude is $0.05 \mathrm{~V}$.

The filament conditions were observed to have a profound effect on the growth rate. Even in the absence of resistive-wall mode growth, the diocotron mode was made to grow at a substantial rate by increasing the filament heating voltage, even by modest amounts. Growth rates exceeding $20 \mathrm{sec}^{-1}$ are observed with heating voltages of 67 volts. Figure 1 shows the mode growth increasing by factors of 50 or more with a change in heating voltage of less than 1 Volt (a 15\% variation). Figure 1 also shows a dependence on bias voltage, with a distinct peak in sensitivity at about -12 Volts and falling substantially by $V_{b}=-8$ or -16 Volts. 
To examine this further, a dedicated bias voltage scan was conducted $-4>V_{b}>-15$ $\mathrm{V}$ at the base pressure. As shown in Figure 2, a narrow peak in mode sensitivity at a filament bias of about $-5 \mathrm{~V}$ is evident. A number of measurements were made to detect whether the emission current, electron line density, temperature, or the initial column density profiles were similarly sensitive to the filament voltage. Neither the filament emission nor the electron density was found to be a function of heating voltage in the range $4.8 \mathrm{~V}<V_{h}<6.5 \mathrm{~V}$. This is a result of the fact that the filament emission is spacecharge limited for $V_{h}>4.8 \mathrm{~V}$ and this range of filament bias voltage. The emission and density increase with $V_{b}$ as expected because the plasma potential follows $V_{b}$, but no peak in density or emission occurs at $-5 \mathrm{~V}$ that is coincident with the strong diocotron mode growth.

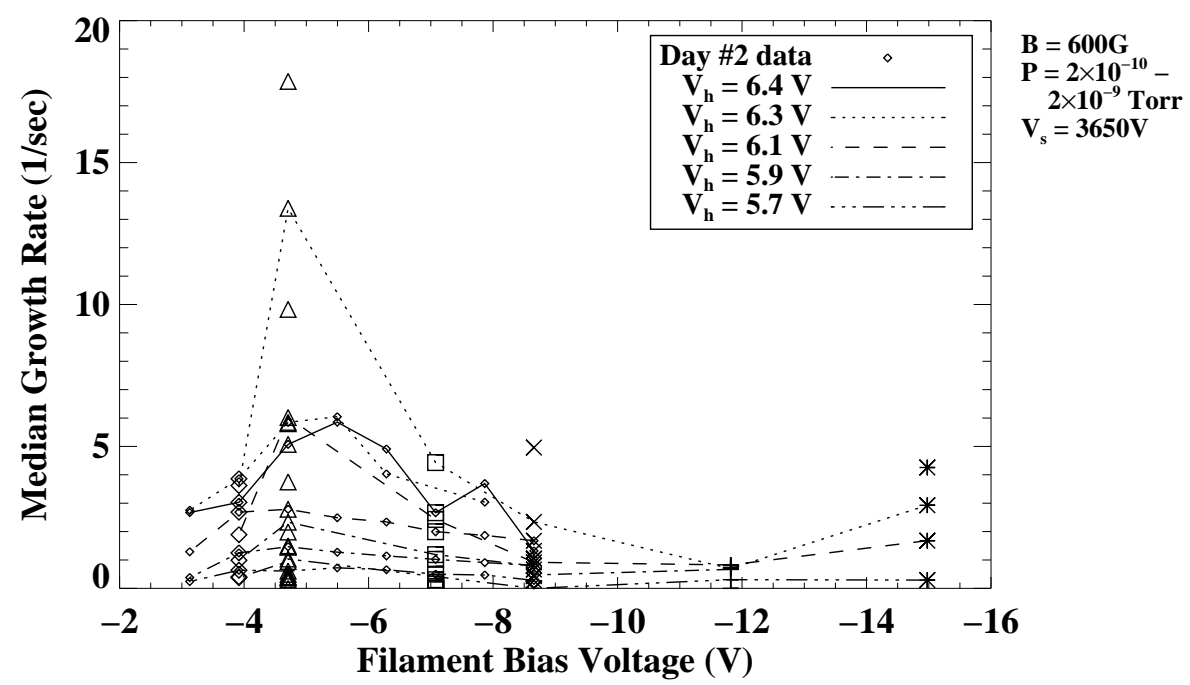

FIGURE 2. Plot of median growth rate of the diocotron mode versus filament bias voltage. Contours of filament heating voltage are indicated. The median growth rate is evaluated between $\mathrm{A}=0.02 \mathrm{~V}$ and the point where $d A / d t$ is a maximum.

To determine whether temperature and profile effects might explain this behavior, filament heating voltage scans for $4.2 \mathrm{~V}<V_{h}<6.7 \mathrm{~V}$ at $V_{b}=-4.7 \mathrm{~V}$ were performed. The perpendicular temperature $T_{\perp}$ is inferred by fitting the measured axially-integrated density profile with a calculated equilibrium and rises linearly from 0.3 to $0.6 \mathrm{eV}$. The parallel temperature $T_{\|}$was determined by measuring the fast electrons escaping from the trap as the discharge is terminated and assuming a Maxwellian parallel velocity distribution. $T_{\|}$is measured to be $1.7 \pm 0.3 \mathrm{eV}$-independent of heating voltage. The estimated electrostatic energy per electron is found to range only from 2.1 to $2.2 \pm 0.1$ eV per electron.

The only obvious difference is that the predicted initial plasma radius changes with $V_{h}$. The bias voltage $V_{b}$ is applied to the center of the filament, and the heating voltage $V_{h}$ is applied across the filament. At low filament bias potentials, $V_{h}$ can exceed $V_{b}$, forcing the bias at the edge of the filament to become positive and suppressing electron emission. As $V_{b}$ is increased, the area of the filament that is positively biased becomes larger and the emitting area smaller. Throughout these measurements at the base pressure, the 
momentum transport rate due to expansion is less than $1.5 \mathrm{sec}^{-1}$, ten times less than the peak diocotron mode growth rate.

The previous data do not indicate how the introduction of neutral atoms affect the mode growth or the filament conditions where the mode growth was observed, so a pressure scan was conducted at $V_{h}=6 \mathrm{~V}$. As shown in Figure 3, the $V_{b}$ envelope for strong mode growth between $4 \mathrm{~V}<V_{b}<9 \mathrm{~V}$ remains. Figure 3 also illustrates that strong mode growth can appear under other conditions; diocotron mode growth is observed for $V_{b}>10 \mathrm{~V}$ as well. The mode growth at the highest pressure in this scan is often nonexponential, and the growth at higher $V_{b}$ is also often delayed for several seconds or preceded by the damping of a small initial mode.

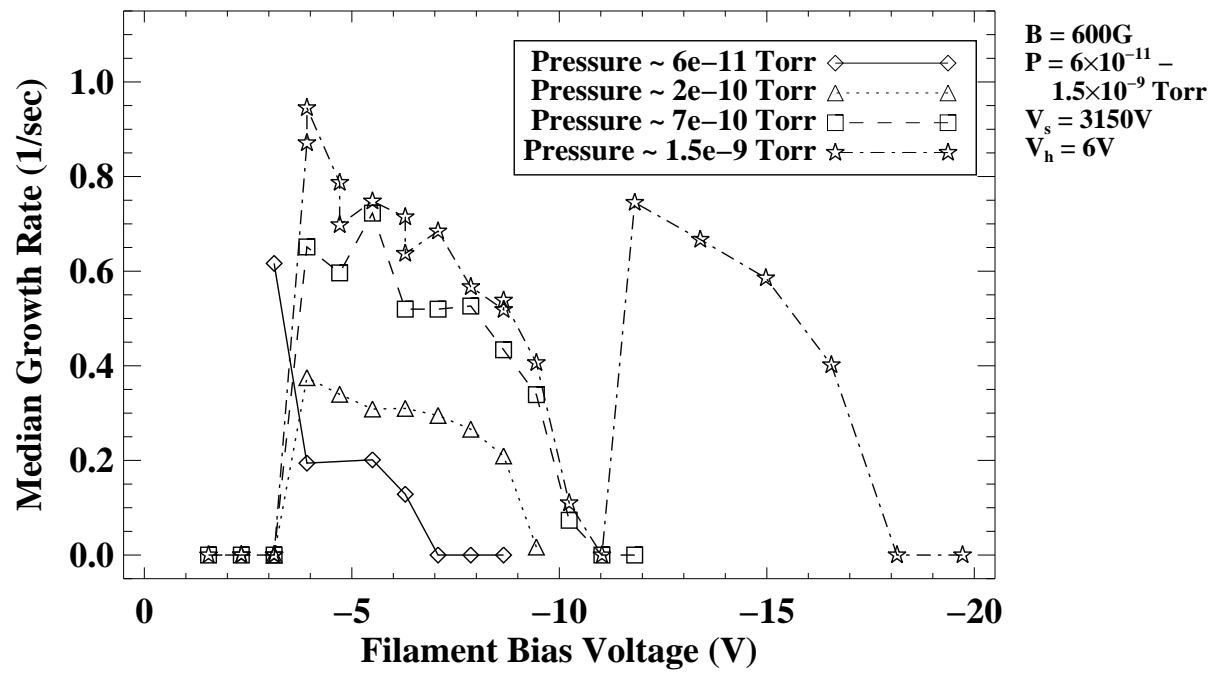

FIGURE 3. Plot of median diocotron mode growth rate versus $V_{b}$ for several values of helium filling pressure. The growth rate is the median value between $\mathrm{A}=0.02 \mathrm{~V}$ and where $\mathrm{dA} / \mathrm{dt}$ is a maximum.

A more detailed measurement of pressure dependence was conducted by simply allowing the base pressure to rise over time as the filament heated the trap. The pressure was allowed to rise from $6 \times 10^{-11}$ Torr to $2 \times 10^{-8}$ Torr. In Figure 4, the mode growth is seen to increase almost linearly with pressure up to $6 \times 10^{-10}$ Torr, a factor of six above the base pressure, above which the mode growth levels off. Also plotted is the scaled value for mode growth that would result from electron-neutral collisions, assuming that the base pressure residual gas is hydrogen and the electron temperature is $1 \mathrm{eV}$ and isotropic. Although the scaling is consistent with the theory of collision-based transport, the scale factor is six orders of magnitude larger, clearly indicating that some additional, strong effect is present.

In summary, it is found that:

- The diocotron mode can be made to grow in response to electron-neutral collisions without resistive forcing by employing low filament bias voltages that produce a low-density $\left(N_{L}=1-2 \times 10^{7} \mathrm{~cm}^{-1}\right)$, small-diameter plasma column.

- The mode growth rate increases strongly with the filament heating voltage, with measured growth rates as high as $20 \mathrm{sec}^{-1}$. 


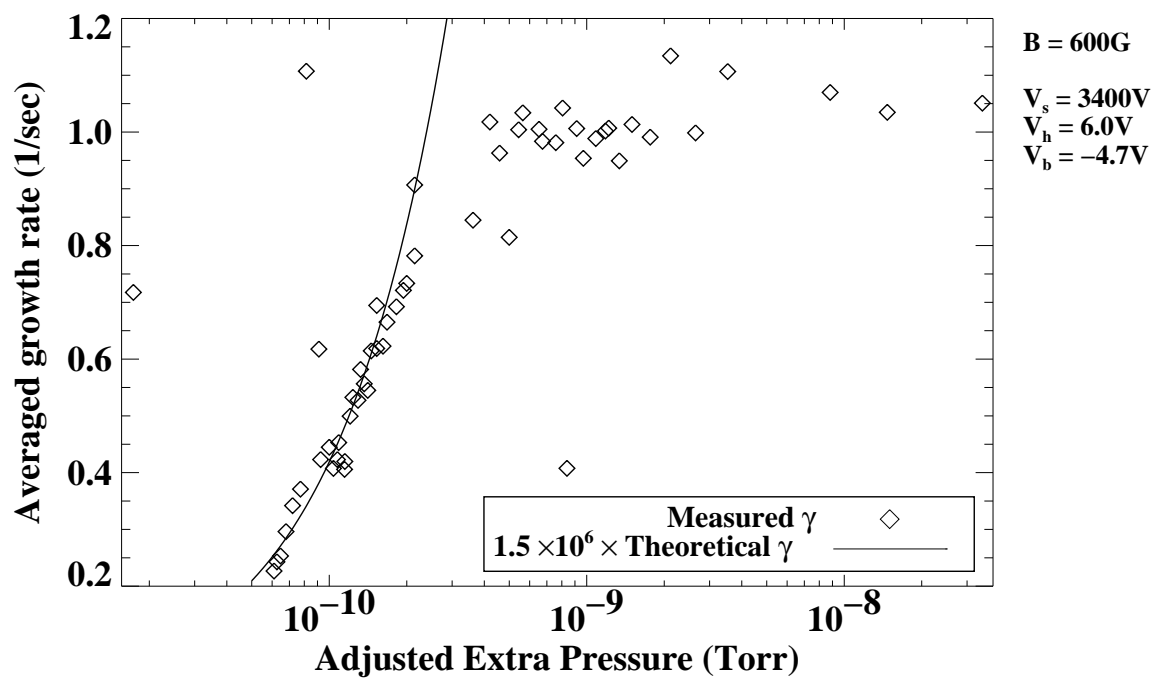

FIGURE 4. Plot of average growth rate to maximum $d V / d t$ of the diocotron mode versus $V_{b}$ for several values of helium filling pressure. The solid line is the mode growth rate predicted from electron-neutral collisions in Eq. (1) multiplied by a factor of 1.5 million.

- The sensitivity of mode growth to pressure for $P<10^{-9}$ Torr is much greater than that previously observed for mode damping.

- The scaling of growth rate with pressure is in agreement with theory (both are approximately linearly proportional), but the growth rates are orders of magnitude larger than predicted for electron-neutral collisions.

This research was supported by the Office of Naval Research and in part by the U.S. Department of Energy.

\section{REFERENCES}

1. Anderegg, F., Schweikhard, L., and Driscoll, C. F., editors, Non-Neutral Plasma Physics IV: Workshop on Non-Neutral Plasmas: AIP Conference Proceedings, Volume 606, American Institute of Physics, Melville, NY, 2002.

2. Bollinger, J. J., Spencer, R. L., and Davidson, R. C., editors, Non-Neutral Plasma Physics III: AIP Conference Proceedings 498, American Institute of Physics, Melville, NY, 1999.

3. Davidson, R. C., Physics of Nonneutral Plasmas, Addison-Wesley, Redwood City, 1990.

4. Fajans, J., and Dubin, D. H. E., editors, Non-Neutral Plasma Physics II, vol. AIP 331, AIP Conf. Proc., New York, 1995.

5. Davidson, R., and Moore, D., Phys. Plasmas, 3, 218-225 (1996).

6. Davidson, R. C., and Chao, E. H., Phys. Plasmas, 3, 2615 (1996).

7. Chao, E. H., Davidson, R. C., and Paul, S. F., J. Vac. Sci. Technol. A, 17, 2050 (1999).

8. Chao, E. H., Davidson, R. C., Paul, S. F., and Morrison, K. A., Phys. Plasmas, 7, 831-838 (2000).

9. Morrison, K. A., Davidson, R. C., Paul, S. F., Belli, E. A., and Chao, E. H., Phys. Plasmas, 8, 3506-3509 (2001).

10. Davidson, R. C., and Chao, E. H., Phys. Lett. A, 219, 95-101 (1996).

11. Davidson, R. C., and Chao, E. H., Phys. Plasmas, 3, 3279 (1996).

12. Kabantsev, A. A., Yu, J. H., Lynch, R. B., and Driscoll, C. F., Phys. Plasmas, 10, 1628-1635 (2003).

13. Kapetanakos, C., and Trivelpiece, A., J. Appl. Phys., 42, 4841-4847 (1971). 


\section{External Distribution}

Plasma Research Laboratory, Australian National University, Australia

Professor I.R. Jones, Flinders University, Australia

Professor João Canalle, Instituto de Fisica DEQ/IF - UERJ, Brazil

Mr. Gerson O. Ludwig, Instituto Nacional de Pesquisas, Brazil

Dr. P.H. Sakanaka, Instituto Fisica, Brazil

The Librarian, Culham Laboratory, England

Mrs. S.A. Hutchinson, JET Library, England

Professor M.N. Bussac, Ecole Polytechnique, France

Librarian, Max-Planck-Institut für Plasmaphysik, Germany

Jolan Moldvai, Reports Library, Hungarian Academy of Sciences, Central Research Institute for Physics, Hungary

Dr. P. Kaw, Institute for Plasma Research, India

Ms. P.J. Pathak, Librarian, Institute for Plasma Research, India

Ms. Clelia De Palo, Associazione EURATOM-ENEA, Italy

Dr. G. Grosso, Instituto di Fisica del Plasma, Italy

Librarian, Naka Fusion Research Establishment, JAERI, Japan

Library, Laboratory for Complex Energy Processes, Institute for Advanced Study, Kyoto University, Japan

Research Information Center, National Institute for Fusion Science, Japan

Dr. O. Mitarai, Kyushu Tokai University, Japan

Dr. Jiangang Li, Institute of Plasma Physics, Chinese Academy of Sciences, People's Republic of China

Professor Yuping Huo, School of Physical Science and Technology, People's Republic of China

Library, Academia Sinica, Institute of Plasma Physics, People's Republic of China

Librarian, Institute of Physics, Chinese Academy of Sciences, People's Republic of China

Dr. S. Mirnov, TRINITI, Troitsk, Russian Federation, Russia

Dr. V.S. Strelkov, Kurchatov Institute, Russian Federation, Russia

Professor Peter Lukac, Katedra Fyziky Plazmy MFF UK, Mlynska dolina F-2, Komenskeho Univerzita, SK-842 15 Bratislava, Slovakia

Dr. G.S. Lee, Korea Basic Science Institute, South Korea

Institute for Plasma Research, University of Maryland, USA

Librarian, Fusion Energy Division, Oak Ridge National Laboratory, USA

Librarian, Institute of Fusion Studies, University of Texas, USA

Librarian, Magnetic Fusion Program, Lawrence Livermore National Laboratory, USA

Library, General Atomics, USA

Plasma Physics Group, Fusion Energy Research Program, University of California at San Diego, USA

Plasma Physics Library, Columbia University, USA

Alkesh Punjabi, Center for Fusion Research and Training, Hampton University, USA

Dr. W.M. Stacey, Fusion Research Center, Georgia Institute of Technology, USA

Dr. John Willis, U.S. Department of Energy, Office of Fusion Energy Sciences, USA

Mr. Paul H. Wright, Indianapolis, Indiana, USA 
The Princeton Plasma Physics Laboratory is operated by Princeton University under contract with the U.S. Department of Energy.

\author{
Information Services \\ Princeton Plasma Physics Laboratory \\ P.O. Box 451 \\ Princeton, NJ 08543
}

Phone: 609-243-2750

Fax: 609-243-2751

e-mail: pppl_info@pppl.gov

Internet Address: http://www.pppl.gov 